\title{
Case study: Monitoring and risk management practices of blue-green algae blooms within the regional municipality of Halton
}

\author{
Ramien Sereshk* and Nicholas Kuchmak* \\ *Halton Region Health Department, Oakville, ON.
}

\begin{abstract}
Cyanobacteria pose a threat to public health in waters affected by seasonal blooms. There have been sporadic occurrences of cyanobacterial blooms at an increasing number of public beaches in Halton Region, Ontario, Canada. Even though cyanobacteria may not be visibly present, the risk of exposure to cyanotoxins remains and requires consideration for an effective risk management and monitoring program. The objective of this case study is to provide best practices that may aid local Health Departments in setting up a cyanobacteria monitoring program. Public health inspectors are responsible for visual monitoring of public beaches that takes place on a weekly basis while conducting routine surveillance. Currently, when cyanobacteria are visually identified, a beach posting is issued. A complete risk assessment is completed to determine the acceptability of reopening the beach for public use. It is recommended to implement an approach that involves both visual monitoring and toxin testing using a field test kit. For a beach to be considered safe for bathing, surveillance should indicate a visual absence of a bloom and microcystin test results below Health Canada's recreational water standard of $20 \mathrm{ppb}$. This case study highlights Halton Region's response to cyanobacteria blooms in recreational waters in accordance with the prescribed protocol and guidance document.
\end{abstract}

Key words: Cyanobacteria, blue-green algae, microcystins.

\section{Introduction}

Cyanobacteria, commonly known as blue-green algae present a threat to public health in waters affected by seasonal blooms. Cyanobacteria are a category of microorganisms that possess similar characteristics to algae and exist in fresh, estuarine, and marine waters (EPA, 2016). Cyanobacteria can multiply rapidly forming visible colonies that appear similar to bright green or olive coloured paint, but may also appear blue in colour as cells begin to die (Global Water Research Coalition, 2009). Some species of cyanobacteria pose a threat to human health through the release of toxins during cell death or when nutrients become limited in the environment (Merel et al., 2013). Exposures to cyanobacteria toxins can occur through several pathways, including intentional or accidental ingestion of drinking water, inhalation, or skin contact with recreational water (Codd et al., 1999). Cyanobacteria may accumulate downwind along shorelines and reservoirs and pose an increased risk of exposure for recreational water users (Graham et al., 2008; Global Water Research Coalition, 2009).

Cyanotoxins are categorized based on the human organ system affected, and they may cause a range of symptoms including gastroenteritis, vomiting, nausea, fever, irritation, and rashes. These symptoms may progress to more severe systemic effects such as hepatic failure, neurological damage, and death (Codd et al., 2005).

Corresponding author: Ramien Sereshk (email: Ramien.Sereshk@halton.ca)
Microcystins are the most commonly found group of toxins associated with cyanobacteria blooms (Aranda-Rodriguez and Jin, 2010). Microcystin toxins primarily target liver cells and can lead to internal hemorrhaging (Stone and Bress, 2007).

Health effects associated with cyanobacteria are an emerging public health issue, and current research has indicated as much as a 10-fold increase of cyanobacteria-related illnesses over the past 100 years (Wood, 2016). Figures from the Center for Disease Control report cyanobacteria have been confirmed or suspected to have caused almost half of the outbreaks associated with untreated recreational water between 2009 and 2010 (CDC, 2014). Furthermore, it is likely the burden of illness attributed to harmful algae is severely underreported as reporting of this illness is voluntary (Craun et al., 2005). In Canada, some jurisdictions have enacted specific cyanobacteria monitoring programs, whereas others manage the risks associated with cyanobacteria blooms on an individual or case-by-case basis (Aranda-Rodriguez and Jin, 2010). This case study will examine previous bloom events occurring in Halton Region during the period between 2014 and 2016 and will discuss risk management strategy and lessons learned.

\section{Background}

Halton Region is located along the north shore of Lake Ontario. The Halton Region Health Department monitors seven public 
beaches along Lake Ontario and various recreational beach waters, including Kelso Lake and Fairy Lake. Seasonal monitoring activities for cyanobacterial blooms are conducted in accordance with the Ontario Ministry of Health and Long-Term Care's Recreational Water Protocol 2016 and Beach Management Guidance Document 2014. Cyanobacteria blooms have occurred in the late summer to early fall each year at La Salle Park in Burlington, Ontario, and sporadically at other beaches along the north shore of Lake Ontario and Kelso Lake.

Student Public Health Inspectors (SPHIs) and the Program Coordinating Public Health Inspectors (PHIs) implement Halton Region's Beach Monitoring Program each season. A preseason assessment and environmental survey is completed for each recreational water site before the beach monitoring season commences in accordance with the Beach Management Guidance Document. The purpose of the environmental survey is to conduct an inspection of the physical beach to identify any changes to structuresand landscapes and identify potential pollution sources and/or any other factor that may affect public health and safety (MOHLTC, 2014). The environmental survey aids in the identification of historical locations of blue-green algae blooms and identifies probable locations for reoccurrence.

During the beach monitoring season, SPHIs are responsible for visual monitoring that takes places on a weekly basis during routine surveillance activities of public recreational beaches. When a visual indication of a cyanobacteria bloom is detected, the SPHIs must follow Halton Region's Policy and Procedures for appropriate corrective actions. This is in keeping with the Beach Management Guidance Document which states: "a public beach posting should be issued until a complete risk assessment can determine the acceptability of using the beach for bathing" (MOHLTC, 2014). Upon posting a public beach, the Halton Region Health Department conducts daily visual monitoring of the affected beach; before 2016 this was conducted over a minimum continuous 2 -week period followed by an additional on-site risk assessment prior to a decision to remove the posting. Surveillance must indicate a visual absence of a cyanobacteria bloom, and completed microcystin tests using a field test kit must show results below a set threshold before a beach is considered safe for bathing. Halton Region sets its Maximum Allowable Concentration (MAC) for microcystins in recreational water at 20 parts per billion ( $\mathrm{ppb}$ ) in accordance with Health Canada's standard of $20 \mathrm{ppb}$ (Health Canada, 2012). The field test kit is used in accordance with the manufacturers' recommendations for microcystins in recreational waters. If concentrations of microcystin are detected at $\geq 20 \mathrm{ppb}$, or visual identification of a bloom occurs, the beach is to remain posted.

It is important to note Halton Region Health Department reports cyanobacteria blooms to the Ontario Ministry of Environment and Climate Change (MOECC), which is the lead authority on pollution source identification and reduction of cyanobacteria blooms in Ontario.

\section{Event summary}

\section{LaSalle Park 2014}

On 4 September 2014, two SPHIs identified the visual presence of a cyanobacteria bloom at La Salle Park in Burlington,
Ontario, a site previously identified as a probable bloom location due to annual occurrences. Once a suspected blue-green algae bloom was observed, an advisory was issued by the Health Department to the respective local municipal parks and recreation department, requiring the posting of bluegreen algae advisory signs. In addition, a notification was communicated to the public through an update on the Halton Region Beach Water Quality website. A continuous twoweek monitoring period of the bloom was completed by the SPHIs. The blue-green algae posting was removed on 15 October 2014 when there were no signs or visual identification of cyanobacteria for a period of two weeks, confirming the bloom had dissipated and microcystin testing had a result of $0 \mathrm{ppb}$.

\section{Beachway Park 2014}

While conducting routine beach surveillance at Beachway Park in Burlington, Ontario, on 4 September 2014, SPHIs recorded visual observations of blue-green algae. No historical blooms had been previously reported at this site. Continuous monitoring was initiated and upon notification the respective municipal parks and recreation department posted signs indicating the presence of blue-green algae. Communications were further distributed by updating the Halton Region Beach Water Quality website. On 5 September 2014, the bloom was not observed, but on 8 September 2014 the bloom was observed and the site was monitored for another two-week continuous period. On 23 September 2014, the notifications and posting of the beach were removed after two weeks of continuous monitoring indicated that the cyanobacteria bloom had dissipated and microcystin toxins were confirmed to be $0 \mathrm{ppb}$.

\section{LaSalle Park 2015}

On 1 September 2015, the SPHIs noted what appeared to be blue-green algae on the surface of the water at La Salle Park, but remained uncertain whether it was indeed a cyanobacteria bloom. The SPHIs conducted a microcystin field test that indicated the microcystin level was greater than the MAC for the Halton Region Health Department. The Program Coordinating PHIs, Health Department management, and allied agencies, (i.e., MOECC, City of Burlington Parks and Recreations Department, and Hamilton Public Health) were notified, and an advisory was posted on the Halton Region Beach Water Quality website in accordance with Halton Region's policy and procedures. Continuous monitoring was initiated and upon notification the respective municipal parks and recreation department posted signs indicating the presence of blue-green algae. Visual identification persisted until 9 September 2015 when the cyanobacteria bloom was not visually detected; however, the bloom was visually identified on 10 September 2015. On 14 September 2015, blue-green algae was not observed but was identified again on the following day restarting the two-week period of continuous monitoring. Visual identification persisted each day until 1 October 2015 when all visual signs of bloom accumulation were absent. Two weeks of continuous monitoring indicated that the cyanobacterial bloom was visually absent, and microcystin testing on 
15 October 2015 confirmed microcystin levels at $0 \mathrm{ppb}$; consequently the posting was removed.

\section{Brant Street Beach 2015}

In addition to the bloom event at La Salle Park, on 1-2 September 2015, blue-green algae was also identified at Brant Street Beach in Burlington, Ontario. Continuous monitoring was initiated and upon notification the respective municipal parks and recreation department posted signs indicating the presence of blue-green algae. Like Beachway Park the year prior, Brant Street Beach represented a site without any historical evidence of bloom accumulation. During the 13 days of continuous monitoring, there were no further visual indications of the cyanobacteria bloom. On the 14th day, the bloom was visually detected and continuous monitoring resumed over the next two weeks. On 2 October 2015, both the lack of visual observations of blue-green algae and microcystin levels measuring $0 \mathrm{ppb}$ indicated that the posting and advisories could be removed.

\section{LaSalle Park 2016}

On 5 July 2016, visual signs of blue-green algae were identified at LaSalle Park. These visual observations triggered the Halton Region Health Department to issue notifications to respective authorities to post the site and included an advisory to be posted on the Halton Region Beach Water Quality website. In accordance with the Beach Management Guidance Document, a risk analysis was conducted. It was determined that LaSalle Park should be permanently posted for the remainder of the season due to the high probability for bloom re-occurrences at this site throughout the summer season because of the annual historical occurrences of blooms over a 10 -year period and the shallow slow-moving waters that favour cyanobacteria growth.

\section{Kelso Lake Beach 2016}

On 18 August 2016, SPHIs conducted routine beach water surveillance and identified a bright green scum along the shore of Kelso Lake in Milton, Ontario. Kelso Lake had not previously been identified as a water body at risk for blue-green algae blooms, and a water sample was taken to support visual observations. Sampling test results determined microcystins at greater than the prescribed MAC of $20 \mathrm{ppb}$. Advisory notifications were issued to local authorities and the Halton Region Beach Water Quality website was also updated. The following morning an onsite risk assessment was conducted by the Program Coordinating PHIs. Previous to this event, a precautionary approach was followed by Halton Region to keep signs posted for a minimum two-week period during the continuous monitoring period due to the unpredictable nature and variability of cyanobacteria blooms. The onsite risk assessment involved microcystin testing that indicated $0 \mathrm{ppb}$ and no visual indications of blue-green algae. It was determined the posting should be removed because of the nature of cyanobacteria blooms to appear and then dissipate within a 24-hour period, even within hours, and the microcystin toxin being below the MAC; however, visual monitoring was to resume continuously for a minimum of 2 weeks as a precaution. The site was monitored until 13 September 2016 when the Kelso staff closed their recreational waters for the remainder of the season as part of their regular annual closure procedures.

\section{Discussion}

Based on historical evidence of seasonal cyanobacteria accumulation, visual identification of cyanobacteria blooms at La Salle Park in 2014, 2015, and 2016 were likely to occur. In contrast, the identification of blue-green algae at Beachway Park, Brant Street Beach, and Kelso Lake demonstrates bloom occurrences in locations that had not previously been recognized as potential sites for cyanobacteria growth. Bloom accumulation is difficult to predict as cyanobacteria growth is dependent on a range of factors, including the varying intensity of available light, gas vesicles to regulate buoyancy, growth rate, nutrient availability, population stability, and temperature (Chorus and Bartrum, 1999). In addition, the release of microcystin toxins is subject to environmental variables, such as wind velocity, sunlight conditions, air and water temperatures, and nutrient availability (Tonk et al., 2005; Davis et al., 2009). The role these factors play in increasing or decreasing the exposure risk to recreational bathers is uncertain, and it is necessary to utilize a risk management approach that considers these factors due to the variability of both bloom formation and the toxin accumulation in recreational waters.

Weekly monitoring for the presence of cyanobacteria blooms is an important intervention to determine if a location is susceptible to bloom accumulation and if a health hazard may be present. Previous research has described monitoring to be an important first step in understanding the prevalence and severity of a bloom occurring within a body of water (Perovich et al., 2008). It is recommended that a reliable and cost-effective monitoring protocol that defines the sampling period, the frequency of sampling, and the analysis methods be created for the protection of human health from the risks associated with cyanobacterial blooms (Koreiviene et al., 2014). Visual monitoring for blue-green algae blooms is a common risk assessment practice used by various public health agencies and authorities throughout North America and requires less resources than an active water sampling program. A 2014 study by Alberta Health Services concluded that visual inspection methods may be an effective practice for risk management in terms of speed and communication with the public, but such visual inspection methods are known to be imperfect due to their subjective nature (Government of Alberta, 2014).

The ability of blue-green algae bloom to move rapidly through the water column creates additional challenges for accurate visual monitoring and risk management of cyanobacteria activity. Cyanobacteria may migrate to different locations within the photic zone of a body of water throughout the day and generally will move towards the surface at night or early morning and downward in the later afternoon (Graham et al., 2008). During the 2014-2016 events as described above, daily indications of a bloom varied up to 13 days, elapsing before the bloom was redetected by the SPHIs. Frequently, multiple days elapsed between visual observations by SPHIs. This illustrates the importance of a risk-management strategy that considers the subjectivity of visual surveillance based on a single site inspection. 
The current literature on the subject of cyanobacteria monitoring in recreational beach waters recommends rapid methods for detecting microcystin levels are necessary to support public health decision-making since microcystin toxins may be present despite a lack of visual evidence (Aranda-Rodriguez and Jin, 2010). Furthermore, once the bloom has disappeared, there continues to be a risk of exposure due to dissolved toxins, as cyanotoxin can remain in the water once the bloom has dissipated (Lawton et al., 1994). Previous research has found microcystins are stable compounds that degrade slowly in sunny and ambient conditions (Tsuji et al., 1995). Additional research has placed the half-life between 7 and 21 days in length (Jones and Orr, 1994; Codd and Bell, 1996; Cousins et al., 1996). The persistence of microcystin toxins to exist in recreational waters without any visual indications of cyanobacteria presence supports the need for rapid toxin testing to be conducted in the field to aid risk-management decisions.

\section{Lessons learned}

The presence of cyanobacteria at La Salle Park in Burlington, Ontario, occurred in consistent locations between 2014 and 2016. The environmental survey provided an important tool for PHIs to track previous sites predisposed to bloom formation and identify areas that posed a higher risk to focus monitoring efforts on high-risk locations. Chorus and Bartrum (1999) recommend the design of a cyanobacteria monitoring program be tailored to each individual body of water and utilize local knowledge of bloom history to enhance the capacity to anticipate bloom formation. Cyanobacteria blooms occurring in approximately the same location along LaSalle Park each year prompted the Halton Region Health Department to issue a permanent posting for the remainder of the season in 2016. The permanent posting of sites that have a high probability of cyanobacteria blooms allows for an evidence-based conservative risk management strategy to be implemented and the allocation of additional monitoring resources to other recreational water use locations.

While the use of historical probabilities of bloom formation was effective in predicting the location of blooms at La Salle Park, the identification of cyanobacteria at other beaches occurred without the availability of historical evidence. The monitoring of public beaches without evidence of historical blooms should continue. The appearance of cyanobacteria at Beachway Park, Brant Street Beach, and Kelso Lake Beach indicate a lack of historical evidence does not indicate a lack of risk for bloom formation. The monitoring program implemented by Halton Region Health Department allows for weekly routine surveillance of all public beaches that may be of potential risk for cyanobacterial blooms.

The variability of cyanobacteria to move throughout a body of water poses additional challenges for effective risk management by public health practitioners. In addition, the potential for microcystins to be present, despite a lack of visual observations of the bloom, increases this challenge. The Halton Region Health Department uses a multiple-barrier approach to effectively identify when a posting should be removed once a bloom is first visualized. The previous bloom events led to the removal of the posting based on a lack of visual observations; this was followed by a field test determining microcystin levels below the MAC. In addition, continuous visual monitoring, confirming the absence of blue-green algae over a period of two weeks, proved to be a necessary monitoring program component due to the risk of bloom reemergence. This multiple-barrier approach recognizes the variability of cyanobacteria blooms to move throughout the water body and acts to identify risks posed by dissolved microcystins that remained in the water despite a lack of visual observations.

\section{Future challenges}

The toxins produced by cyanobacteria pose several challenges for effective public health risk management during blue-green algae blooms. Toxins have been reported to be highly variable both within and between individual blooms (Codd and Bell, 1985). Previous studies indicate significant toxicity differences can occur within meters in the same bloom and within hours of bloom formation (Carmichael and Gorham, 1981). Furthermore, not all strains of cyanobacteria produce harmful toxins, and one species may produce blooms of several strains, both of the nontoxic and toxic variety simultaneously in the same body of water (Vézie et al., 1998). Other monitoring strategies use both cyanobacteria cell counts and chlorophyll-a concentrations to indicate bloom presence but have been reported to overestimate the risk posed by toxins, since chlorophyll-a is produced by many harmless species (Loftin et al., 2016). Relying on visual observation methods alone may activate beach postings or advisories, despite the species within the bloom being the nontoxic.

\section{Acknowledgements}

This case study was made possible due to the active guidance and support of Halton Region's Medical Officer of Health, Dr. Hamidah Meghani; Director of Healthy Environments and Communicable Diseases, Matt Ruf; Manager of Environmental Health, Nicole Mathews; and Public Health Inspector, Anthony Colaco. It is important as well to gratefully acknowledge the assistance of the following agencies for their guidance and resources: City of Hamilton Public Health, Environment Canada, Haliburton, Kawartha, Pine Ridge District Health Unit, Health Canada, Ontario Ministry of the Environment and Climate Change, Ontario Ministry of Health and LongTerm Care, Peterborough County-City Health Unit, and Public Health Ontario.

\section{References}

Aranda-Rodriguez, R., \& Jin, Z. 2010. Evaluation of field test kits to detect microcystins: 2010 study. Available at: https://www.epa.gov/ sites/production/files/2014-08/documents/microcystins-testkitcanada.pdf [accessed 5 June 2016].

Carmichael W. W., \& Gorham, P. R. 1981. The mosaic nature of toxic blooms of cyanobacteria. . In: Carmichael WW. (ed.). The water environment: Algal toxins and health, pp. 161-172. New York: Plenum. doi: 10.1007/978-1-4613-3267-1_12.

Center for Disease Control (CDC). 2014. Recreational water-associated disease outbreaks - United States, 2009-2010. MMWR. 63(01): 6-10.

Chorus, I., \& Bartram, J. (eds.). 1999. Toxic cyanobacteria:. A guide to their public health consequences monitoring and management. London: World Health Organization. 
Codd, G. A. and Bell, S. G. 1985. Eutrophication and toxic cyanobacteria in freshwaters. Wat Pollut. Control. 84: 225-232.

Codd, G. A., \& Bell, S. G. 1996. The occurrence and fate of blue-green algal toxins in freshwaters. National Rivers Authority R and D Report 29. London: Her Majesty's Stationery Office.

Codd, G. A., Bell, S. G., Kaya, K., Ward, C., Beattie, K. and Metcalf, J. 1999. Cyanobacterial toxins, exposure routes and human health. Eur. J. Phycol. 34(4): 405-415. doi: 10.1080/ 09670269910001736462.

Codd, GA, Morrison, LF, Metcalf, JS. (2005). Cyanobacterial toxins: Risk management for health protection. Toxicol. Appl. Pharmacol. 20: $264-272$.

Cousins, I. T., Bealing, D. J., James, H. A. and Sutton, A. 1996. Biodegradation of microcystin-LR by indigenous mixed bacterial populations. Water Res. 30: 481-485.

Craun, G. F., Calderon, R. L. and Craun, M. F. 2005. Outbreaks associated with recreational water in the United States. Int. J. Environ. Health Res. 15: 243-262.

Davis, T. W., Berry, D. L., Boyer, G. L. and Gobler, C. J. 2009. The effects of temperature and nutrients on the growth and dynamics of toxic and non-toxic strains of microcystis during cyanobacterial blooms. Harmful. Algae. 8: 715-725.

Environment Protection Agency (EPA). 2016. Cyanobacteria/cyanotoxins. Available at: https://www.epa.gov/nutrient-policy-data/ cyanobacteriacyanotoxins [accessed 21 June 2016].

Global Water Research Coalition. 2009. Cyanobacateria manual. Available at: http://www.waterra.com.au/cyanobacteria-manual/ Chapter3.htm\#Sample [accessed 21 June 2016].

Government of Alberta. 2014. Alberta cyanobacteria beach monitoring 2010-2013. Available at: http://www.health.alberta.ca/documents/Cyanobacteria-Algae-Monitoring-2014.pdf [accessed 18 June 2016].

Graham, J. L., Loftin, K. A., Ziegler, A. C., \& Meyer, M. T. 2008. Guidelines for design and sampling for cyanobacterial toxin and taste-and-odor studies in lakes and reservoirs:. U.S. Geological Survey Scientific Investigations Report 2008-5038. 39 p. Available at: http://pubs.usgs.gov/sir/2008/5038/pdf/SIR20085038.pdf [accessed 2 Dec 2016].

Health Canada. 2012. Guidelines for Canadian recreational water quality -Third edition. Available at: http://healthycanadians.gc.ca/ publications/healthy-living-vie-saine/water-recreational-recreative-eau/index-eng.php?page $=11$ [accessed 21 June 2016]

Jones, G. J. and Orr, P. T. 1994. Release and degradation of microcystin following algicide treatment of a Microcystis aeruginosa bloom in a recreational lake, as determined by HPLC and protein phosphatase inhibition assay. Water Res. 28: 871-876.
Koreivienė, J. Olga, A. Kasperovičienè, and J. Burškytė, V. 2014. Cyanotoxin management and human health risk mitigation in recreational waters. Environmental Monitoring and Assessment, 186(7): 4443-4459. doi: 10.1007/s10661-014-3710-0.

Lawton LA, Edwards C, and Codd GA. 1994. Extraction and high-performance liquid chromatographic method for the determination of microcystins in raw and treated waters. Analyst 119(7): $1525-1530$.

Loftin, K. A., Graham, J. L., Hilborn, E. D., Lehmann, S. C., Meyer, M. T., Dietze, J. E. 2016. Cyanotoxins in inland lakes of the United States: Occurrence and potential recreational health risks in the EPA National Lakes Assessment. Harmful Algae. 56: 77-90. doi: 10.1016/j.hal.2016.04.001.

Merel, S., Walker, D., Chicana, R, Snyder, S., Baures, E. and Thomas, O. 2013. State of knowledge and concerns on cyanobacterial blooms and cyanotoxins. Environ. Int. 59: 303-327. doi: 10.1016/j. envint.2013.06.013.

Ontario. Ministry of Health and Long-Term Care (MOHLTC). 2014. Beach management guidance document. Toronto: Queen's Printer for Ontario.

Ontario. Ministry of Health and Long-Term Care (MOHLTC). 2016. Recreational water protocol. Toronto: Queen's Printer for Ontario.

Perovich, G., Dortch, Q., \& Goodrich, J. 2008. Causes, prevention, and mitigation workgroup report. In Hudnell H. K. (ed.). Cyanobacterial harmful algae blooms: State of the science and research needs, pp. 185-217. New York: Springer.

Stone, D. and Bress, W. 2007. Addressing public health risks for cyanobacteria in recreational freshwaters: The Oregon and Vermont framework. Integr. Environ. Assess. Manag. 3(1): 137-143.

Tonk, L., Visser, P. M., Christiansen, G., Dittmann, E., Snelder, E. O. F. M., Wiedner, C. 2005. The microcystin composition of the cyanobacterium planktothrix agardhii changes toward a more toxic variant with increasing light intensity. Appl. Environ. Microbiol. 71: 5177-5181.

Tsuji, K., Watanuki, T., Kondo, F., Watanabe, M. F., Suzuki, S., Nakazawa, H. 1995. Stability of microcystins from cyanobacteria--II. Effect of UV light on decomposition and isomerization. Toxicon. 33(12): 1619-1631.

Vézie, C., Brient, L., Sivonen, K., Bertru, G., Lefeuvre, J.-C. and Salkinoja-Salonen, M. 1998. Variation of microcystin content of cyanobacterial blooms and isolated strains in Lake Grand-Lieu (France). Microbial. Ecol. 35(2): 126-135.

Wood, R. 2016. Acute animal and human poisonings from cyanotoxin exposure - A review of the literature. Environ. Int. 91: 276-282. doi: 10.1016/j.envint.2016.02.026. 